\title{
The Impact of the Digital Transformation of Business on Corporate Governance. An Overview of Recent Studies
}

\author{
Ilya Ivaninskiy \\ $\mathrm{PhD}$ student \\ ORCID \\ E-mail: iivaninskiy@hse.ru
}

Department of Finance, National Research University Higher School of Economics, Moscow, Russia

Journal of Corporate Finance Research, Vol. 13, No. 3, pp. 35-47 (2019)

DOI: https://doi.org/10.17323/j.jcfr.2073-0438.13.3.2019.35-47

Received 15 July 2019 | Peer-reviewed 10 August 2019 | Accepted 3 September 2019 


\section{The Impact of the Digital Transformation of Business on Corporate Governance. An Overview of Recent Studies}

\section{Abstract}

This article presents a survey of recent studies on the impact of digitalisation, and particularly blockchain technology, on corporate governance and the principal-agent conflict in companies. The principal-agent conflict has been a centerpiece of the corporate governance research for more than 40 years. However, recent technological developments, and blockchain in particular, has created new avenues for exploration.

We survey the implications of blockchain for the principal-agent conflict in three parts: 1) the organisational environment, and the creation of the conflict; 2) common observable instances of conflict; 3) actions necessary to maximise the value of blockchain implementation. We limit the studied conflict to the relationship between shareholders and management. We also limit the blockchain use cases to those currently in testing. The applications for blockchain in securities trading and for corporate functions automation via 'smart' contracts are both analysed. We also evaluate the implications for investor activism.

Our results indicate that passive investor behaviour is at the core of the environment that creates conflict. One of the key drivers of low activity is a non-transparent voting process resulting in low participation rates. Studies indicate that blockchain can solve this issue, thus mitigating the conflict, and is an attractive proposition for board members. The most frequent instances of conflict are related to the composition of boards of directors and compensation schemes observed at shareholder voting. Using blockchain for settlement would eliminate ambiguity in shareholder registers and prevent such strategies as "empty voting". Smart contracts promise automation of governance functions like audit, which also weakens conflict. Even skeptics agree that voting is a promising application for blockchain. However, there is evidence that blockchain poses its own problems, and that smart contracts are associated with practical risks. Some critics argue that blockchain is less efficient than conventional corporate procedures.

Blockchain is among the top digital technologies that business leaders have to monitor closely. As such, this overview of the most up-to-date thinking on the subject is relevant for anyone interested in the future of corporate governance and the digitalisation of business processes. This evaluation serves to highlight the current status of this innovative resource, outlining for both professionals and newcomers what exactly blockchain's potential uses and implications are, while also outlining where a lack of quantitative research creates opportunities for further contributions to the research field. This study will also be instructive for those investigating blockchain implementation and the optimal characteristics of the solution.

Key words: corporate governance, blockchain, digital transformation, board of directors, corporate voting, proxy contest JEL classification: G32, G34 


\section{Introduction}

Since the publicationarticle of M. Jensen and W. Meckling (1976) [1], and the earlier work by A. Berle and G. Means [2], the principal-agent conflict has been a mainstream framework of corporate governance research. Managers and shareholders have diverse objectives. This sometimes leads to situations where management makes suboptimal decisions for the shareholders, and even for the management itself, in the long run (e.g. by investing less in innovation [3]). This situation results in conflicting shareholder proposals for annual shareholder meetings [4], and proxy contests and other forms of activism $[5 ; 6]$. While the topic of the principal-agent conflict is as relevant as ever, recent technological developments have served to increase its significance.

We appreciate the fact that principal-agent conflict is not just between shareholders and management, as it includes bondholders [7] and other stakeholders [8]. However, for the purpose of this article, we limit the conflict to the interaction between shareholders and management, since it is the most well-researched area.

Blockchain is a technology that arguably presents the most transformative potential of any other [9-11]. According to M. Swan [12], “...(the) blockchain concept... is a new organising paradigm for the discovery, valuation, and transfer of all quanta (discrete units) of anything, and potentially for the coordination of all human activity at a much larger scale than has been possible before".

Blockchain has the potential to change fundamentally alter the value creation and distribution mechanisms within a firm, which in turn affects the principal-agent conflict. We cluster the potential impact of blockchain on the conflict into three categories: 1) the organisational environment, and the creation of the conflict; 2) common observable instances of conflict; and 3) actions necessary to maximise the value of blockchain implementation. Understanding these changes has important practical consequences. It will help both shareholders and managers embrace the opportunities offered by blockchain, define approaches in order to help manage risks, and ultimately develop strategies for sustainable cash flow generation.

The technology and business community has embraced the opportunities offered by blockchain, and the scholarly discussion has been gaining momentum as well, especially in computer science literature [e.g. 13; 14]. The most well-researched blockchain-related topic in the field of corporate finance so far has been cryptocurrencies such as Bitcoin [e.g. 15-17]. The cryptocurrencies research has led to further development in other fields. M. Holub and J. Johnson [18], conduct a systematic review of Bitcoin's influence and expansion on academic research fields. Fundamental shifts in value creation and distribution mechanisms start to get attention as well. In this article, we review the existing studies on blockchain and corporate governance and identify key blank spots for potential new research.
The rest of this article is structured as follows: we briefly review the blockchain technology and its application;we review the literature according to the three categories of impact of blockchain on corporate governance mentioned above, andwe provide conclusions and identify the most promising areas for future research.

\section{Brief overview of blockchain technology}

There are multiple detailed articles describing blockchain technology in different levels of detail for readers of various levels of expertise. For example, a book by M. Swan [12] or an article by D. Yermak [9] for a review of the technology and its main concepts and applications, or an article by F. Hawlitschek et al. [19] for a more technical overview coupled with a technical literature review. However, we believe it is important to outline the key concepts in this article.

According to F. Hawlitschek et al., "A blockchain is a database shared among its users that allows them to transact valuable assets in a public and pseudonymous setup without the reliance on an intermediary or central authority... From a technical perspective, a blockchain is a composition of a distributed database, a decentralised consensus mechanism, and cryptographic algorithms. More specifically, transactional data is stored in a potentially infinite sequence of cryptographically interconnected data blocks. These blocks are ordered by a decentralised time stamping algorithm, which allows users to vote on the validity of database updates and eventually agree on the correct order of transactions and a shared system state at any given point in time. As a result, the users of a blockchain system can interact without the need for a central authority that resolves conflicting views of the correct order of transactions" [19].

Broadly speaking, research literature covers two types of blockchain application that affect the principal-agent conflict: a reliable distributed ledger coupled with a platform for transactions, and smart contracts. We will briefly describe both.

\section{A reliable ledger}

As per V. Magnier and P. Barban in their 2018 composition, "by itself, the blockchain is a public register... As there is no third party or central authority overseeing the system, the public itself must be able to access all the transactions occurring on a blockchain.... Each blockchain can...be downloaded by all users, containing all the past transactions since its creation... In order to manipulate the register, it would be necessary to change all the past history of the register on a global scale: each and every version of the blockchain on all existing and active nodes would have to be similarly impaired. Such a manipulation would need an overwhelming computing power..." [20]. This blockchain application helps the creation of basic cryptocurrencies such as Bitcoin. From the corporate governance point of view, the main consequence 
of this application is full transparency on the recorded transactions. We will discuss the concrete implications in the next sections of the article.

\section{Smart Contracts}

Smart contracts are obligations stored in computer code that execute themselves without control of third parties $[12 ; 21]$. While smart contracts were envisioned as early as 1990 s $[10 ; 22 ; 23]$, the first real world applications were created only with the creation of blockchain.

Smart contracts are the blockchain application with strong enough potential to challenge the nature of the principal-agent conflict. Smart contracts can reduce the power of management and create transparency for shareholders [24; 25]. Various researchers have suggested application areas for smart contracts for financial markets [26; 27], in trade finance [10], for supply chain management [28], government services [29], and the energy sector [30]. Experiments have been conducted around creating entire organisations without management (so called DAOs) [31; 32]. We will review these experiments later in the article.

As one may imagine, the two blockchain applications mentioned above have different implications for the principal-agent conflict. While using blockchain purely as a ledger is very pragmatic and may generate positive impact in the near future, the use of smart contracts has a much bigger potential, but will most likely take more time to unfold. In the next sections of the article we will review the implication of both types of blockchain applications.

\section{The organisational environment, creating the conflict}

The conflict between shareholders and managers arises when the management team and, most notably, the CEO gains disproportionate power in the organisation, allowing it to overpower the board of directors [33-35].

At the core of the environment which makes the conflict possible, is passive investor behavior [36]. According to a study by Broadridge Financial Services, which tabulates votes in most U.S. corporate elections, voter turnout rates of $83 \%$ are reported for institutional investors but only $28 \%$ for household retail investors ${ }^{1}$. Studies show that investors do not actively monitor portfolio firms [37; 38] or blindly follow recommendations of proxy-voting advisors such as ISS $[39 ; 40]$. This is more relevant in the case of homogeneity among the shareholders [41; 42]. The growth of "index funds" increases the issue even further [38].

A non-transparent voting process that is often influenced by management is one of the primary reasons for a low shareholders voting turnout. Examples of problems with voting include inexact voter lists, incomplete distribution of ballots, and sometimes, chaotic vote tabulation [43]. This happens because participating in the voting "costs" a lot of effort while it brings very limited benefit for a small shareholder, which is in line with political voting theory [44]. Empirical research shows that reducing the turnout costs for small shareholders increases their participation at AGMs [45].

Multiple studies suggest that voting based on a blockchain would significantly improve the situation with voting. The articles referenced at $[9 ; 46]$ each argue that corporate voting based on blockchain would be much more transparent due to "faster, more precise vote tabulation and equal real-time transparency of the likely voting outcome for both management and dissident shareholders". This would resolve ambiguities about the outcomes of close elections (where the vote split is close to 50/50). As a result, management will lose some of its disproportionate power which will be noticed, for example, in fewer accepted management proposals related to compensation and governance.

C. Van der Elst and A. Lafarre[45] point out that blockchain would make voting, especially on annual general meetings more convenient. Shareholders would be able to vote during a short period on one or more voting items from their own desks and do not have to fill out any registration or proxy form. This would make decision-making faster, which will cut costs to companies. The same authors, in a later article [47], point out that with blockchain remote voting "becomes yet more transparent and reliable and thus further reduces the transaction costs to shareholders, which further stimulates (small) shareholder participation rates". Blockchain voting would solve a problem of identification of actual shareholders, which would facilitate participation.

W.A. Kaal [48] offers a more radical view on the implications of blockchain for voting. The author suggests that blockchain would allow firms to avoid certain corporate governance procedures like annual shareholder meetings altogether if the voting can be conducted using blockchain.

Some authors [see for example 49], who are skeptical about using existing blockchain solutions for accounting and ownership reporting purposes, are optimistic about using it for corporate voting.

S.E. De Falco et al. [50] conducted a survey of members of the board of directors and of institutional investors on expectation associated with blockchain technology. The authors confirm the attractiveness of blockchain for voting for board members. However, "the respondents said they were neutral with respect to the possible impact of the blockchain on the corruptibility to which the shareholders' meeting is subject". This shows that while the researcher community generally accepts the benefits of blockchain for voting, industry practitioners are not yet as optimistic.

Multiple articles suggest designs of systems for shareholder voting [e.g. 51; 52]. On top of that, currently there are 
several large-scale blockchain implementation experiments in process. See [47] for a comprehensive table of efforts with a status as of 2018 .

One of the first pilots was Nasdaq's project for e-voting in Estonian AGMs in 2016. In February 2016, Nasdaq announced, in cooperation with the Estonian government, a blockchain based e-voting application which allows shareholders that hold shares in companies listed on the Tallinn Stock Exchange (belonging to Nasdaq) to vote remotely in AGMs [47]. Based on this pilot scheme, Nasdaq expanded blockchain usage to South Africa and is now also using blockchain for trading of mutual funds. The German Central Bank, together with the Deutsche Börse announced in November 2016 the development of a prototype of blockchain technology to settle securities [27].

Another example is a blockchain-based process for proxy voting introduced by CSD Working Group on Distributed Ledger Technology, which is a Consortium of Central Securities Depositories (NSD in Russia, Strate in South Africa, Six Securities Services in Switzerland, Nasdaq Nordic, and DCV in Chile), see [47] for details. The previously-mentioned Broadridge, a large proxy voting business, successfully piloted the proxy voting progress process in cooperation with J.P. Morgan, Santander Investment and Northern Trust in 2017 [53]. Currently Broadridge is expanding the effort to the territory of Japan [54].

One of the most recent pilots schemes is to establish electronic voting through the adoption of distributed ledger technology (DLT) in the Asia Pacific region by SWIFT. The project is in cooperation with securities software provider SLIB, Singapore Exchange (SGX), DBS Bank, Deutsche Bank, HSBC, and Standard Chartered Bank in Asia [55].

Yet, despite the overall positive attitude towards blockchain for corporate voting, there are, of course important issues to consider. For example, A. Lafarre and C. Van der Elst [47] highlight several issues. If voting is moved to blockchain, would traditional shareholder meetings still be necessary? If blockchain-based voting replaces the traditional shareholder meetings, will it be able to replace the forum function of the meeting? V. Maginer and P. Barban [20] argue that blockchain increases transparency of ownership, which may not be desirable to all shareholders. Authors also point out that using blockchain poses a question of liability in case of a problem. For example, if a mistake with an annual shareholder meeting results occurs, who is the liable party?

To sum up, we can see that there is a generally positive attitude towards using blockchain for corporate voting from those engaged in research as well as practitioners as it promises to solve, at least partially, long lasting problems with voting and thus mitigate the principal-agent conflict. However, all the studies surveyed are conceptual in nature. Whether the application of blockchain actually results in lower conflict within an organisation needs to be tested via empirical research.
Academic thinking on the implementation of blockchain for improving the environment expands beyond just updating the technology behind corporate voting. D. Yermak [9] argues that if instead of traditional corporate structures the firm ownership was based on the blockchain, this would create an environment where the shareholders would be automatically included in the decision making process, not just at the annual voting. This would drastically increase the governance activity by the shareholders. However, on the flipside, if a company applied smart contracts at scale, this would mean that the firm is steered in the right way almost automatically and decreases the need for active monitoring. We explore the state of research and current pilot projects further in this article.

\section{Common observable instances of the principal-agent conflict}

As mentioned earlier, we limit our analysis to the conflict between the shareholders and management. The easiest environment to observe this conflict is around corporate voting, where conflicting options are proposed by management and shareholders including both shareholder proposals and proxy contests [56]. We looked at voting as a technical process in the previous section of the article. In this section, we review the blockchain influence on the common reasons causing the conflicts at voting. On top of that, we have a closer look at investor activism as a special type of conflict.

The most common reasons for the conflict are the board of directors elections [57] and compensation schemes [58]. This is understandable, as those are classic corporate governance mechanisms. Multiple studies provide discussion on the size and structure of the board of directors [59-61], and on incentive schemes, usually aimed at increasing insider ownership [e.g. 62]. However, these and similar mechanisms rely on human decisions. Solutions based on blockchain have the potential to reduce the amount of human judgement and bring transparency to the next level [21].

In the first section of this article, we mentioned two types of blockchain application: as a ledger and smart contracts. While using blockchain as a ledger for transactions with a company's shares has similar influence on both instances of conflict, using smart contracts has different implications. We structure this section accordingly: first, we explore the impact of blockchain as a ledger; then we look separately at the impact of smart contracts for the board and compensation. Finally, we will end with a look at shareholder activism.

\section{Using blockchain as a ledger for securities transactions}

While the opaque voting process described above stimulates the conflict, other factors also contribute. One of the strategies used in corporate voting is so called 'empty voting', a situation where an investor votes with shares borrowed immediately before the vote, thus enlarging 
his voting power. This is possible due to a limited speed of information dissemination on transactions with the company's securities. Most studies surveyed agree that the clearing and settlement of transactions with a company's securities using blockchain instead of traditional ledgers would potentially stop this practice $[26 ; 27 ; 63]$. Recording transactions with a security in blockchain is instantaneous and hence creates immediate transparency vis-a-vis ownership. Hence, all the stakeholders would be immediately aware of the voting rights distribution [9; 48]. Greater transparency would make conflict at voting more problematic and hence, we may expect that it would become less common.

D. Yermack [9] points out that on top of making empty voting more problematic, registering transactions using blockchain would also limit insider trading by management, since all the transactions would become more visible. A reduction in insider trading would further reduce the conflict since it won't position the management in a more favorable position to other shareholders.

There are of course certain risks associated with greater transparency. V. Magnier and P. Barban point out that if all transactions of management were immediately known to the general public, this might create more volatility with the company's shares [20].

As with the use of blockchain for voting, there are several practical implementations of blockchain for stock trading. Multiple stock exchanges, e.g. Nasdaq, Australian Stock Exchange, London Stock Exchange, and Moscow Exchange are piloting projects in this regard [47]. One of the most notable pilot projects is an effort by the Depositary Trust and Clearing Corporation, the sole provider of clearings, settlement, and custody for the US cash securities markets. Right now it is in the final stages of building a blockchain platform for credit derivatives clearing and settlement which is supposed to go live in 2019.

While the main goal of the pilot implementations described above is not a reduction of the principal-agent conflict, we can expect that it will happen as a result.

\section{Applying smart contracts to mitigate conflicts related to the board of directors}

Proposals concerning the composition of boards of directors, directors' independence, compensation, and qualifications are among the most popular proposal types that shareholders propose for voting at annual shareholder meetings [4]. The proposals related to board composition proposed by management have one of the lowest support rates [42]. It is natural for management to try to slate the board with as many "friendly" members as possible, while it is equally natural for shareholders, particularly the minority ones, to try to bring in independent directors to keep the management under control [64]. However, in a majority of cases, management effectively chooses the board, and not the other way around, as it is meant to happen [65-68]. This effectively means that management wins in the conflict.
While the implementation of blockchain for securities clearing and settlement can mitigate the conflict through identification of the securities owners, using smart contracts in particular can generate a much greater effect. C. Van der Elst and A. Lafarre [45] argue that certain technical functions of the board of directors would no longer be necessary. For example, in the EU a board of directors has a co-optation right - a right to temporarily elect a new board member if a director resigns between two AGMs. If voting is done using blockchain, this decision could be done directly by the shareholders.

There are arguments that in an organisation actively using smart contracts, certain board functions could be simplified and even automated. An example of such a function is audit. Audit is one of the major functions of boards of directors [69], and more active and independent boards execute this function more effectively, preventing earnings manipulation by management [70]. Several authors argue that blockchain can be used to generate immutable accounting records and hence drastically simplify and increase the quality of audit $[9 ; 63 ; 71]$. N. Rückeshäuser [72] points out that "the growing interest in this topic is also reflected by the formation of several start-ups offering blockchain-based services for decentralised bookkeeping, such as Factom or Scorechain".

The automation of this board function would weaken the conflict in two ways. First, it would allow boards to focus on strategic questions rather than technical ones, which would better serve the shareholders. Second, this would exclude the human factor from control functions and make them more accurate.

However, there are critics of blockchain for accounting. N. Rückeshäuser [72] argues that while blockchain could be useful for audit simplification, it still can be subject to fraudulent actions by management in its current form. Rückehäuser suggests ideas on how to improve the current blockchain approach to fix the problem.

Automating technical functions of the board of directors is not the most radical usage of blockchain. W.A. Kaal [48] and D. Yermack [9] argue that the application of blockchain de facto gives more power to shareholders to control management and hence decreases the conflict intensity and the need for the board as an instrument.

Perhaps the most extreme governance opportunity promised by smart contracts is the idea of decentralised autonomous organisations (DAOs). DAOs were originally proposed by V. Buterin [25] - the creator of the Ethereum blockchain, which serves as a platform for most smart contracts. M. Swan [12] describes DAOs as “... a concept derived from artificial intelligence. Here, a decentralised network of autonomous agents perform tasks, which can be conceived in the model of a corporation running without any human involvement under the control of a set of business rules. In a DAO, there are smart contracts as agents running on blockchains that execute ranges of prespecified or preapproved tasks based on events and changing conditions". 
While the concept may seem remote, there have already been trial implementations of it. A. Kristof [32] describes a DAO investment fund built on the Ethereum platform. The fund raised 150 million dollars with the promise that only the investors would decide which projects to pursue via the usage of smart contracts. However, the computer code that encoded the smart contracts contained a minor loophole that allowed a group of hackers to freeze a significant part of the funds. To get the money back to the investors the founders of the Ethereum platform altered the computer code affecting the entire platform. The debate is still open as to whether it was an appropriate action. The very idea of blockchain and smart contracts is that the computer code is more trustworthy than people are. Some experts argue that the investors should have been more accurate studying the code before investing money [73].

This failed case showed us that while automation eliminates the original conflict, it creates a whole universe of new risks and requires a new set of capabilities. Investors and organisations need to build IT capabilities that enable them to maximise the value of blockchain while mitigating the risks.

\section{Compensation schemes}

Equity-based compensation schemes aimed at aligning incentives for shareholders and managers are one of the main tools of principal-agent conflict mitigation. $\mathrm{H}$. Enayati et al. [74] show that up to $100 \%$ of Fortune 500 companies use compensation schemes linked to the total shareholder return measure depending on the industry. Yet, despite this, votes on managerial compensation still cause a lot of disagreement.

As was mentioned in the first section of this article, smart contracts allow automated execution of commitments without the involvement of a third party. Compensation is an example of such a commitment between the shareholders and the employees of a firm. If management's compensation is encoded in a smart contract that links it to the firm's performance, the conflict between management and shareholders becomes impossible, as everything is agreed and fixed at the beginning of the relationship.

The surveyed researchers generally agree on the role of smart contracts as described above. A. Wright and P. De Filippi [46] suggest a very basic form of impact of smart contracts for compensation. The authors propose that "smart contracts could be used to enable employees to be paid on an hourly or daily basis with taxes remitted to a governmental body in real time". D. Yermack [9] agrees that smart contracts may be used for compensation, and for automatic payments when performance goals are achieved.

W.A. Kaal [48] views executive compensation as a part of agency costs. The author argues that the application of blockchain for the principal-agent conflict will allow one to lower the agency costs overall, including those created by executive compensation.
However, as with the case for the board of directors, there are of course risks associated with introducing smart contracts for compensation. W.A. Kaal [48] acknowledges that while encoding compensation to smart contracts would theoretically negate the conflict, troubles similar to the case of DAO are highly probable, e.g. a fraudulent management can take advantage of a glitch in a computer code. The case of the DAO investment fund mentioned above is the perfect example of when a smart contract functions in wrong way.

There is a topic connecting cryptocurrencies and compensation schemes that currently receives a relatively modest coverage in the research literature - using blockchain-based tokens for compensation. In the first section of the article we mentioned ICOs as a blockchain-enabled way of fundraising. In an ICO, issued tokens contain and represent the value of a future project. However, a company may also issue tokens backed by an existing asset of a company. These tokens are then called asset tokens or security tokens since they resemble a company-issued security. L. Oliveira et al. [75] provide an analysis of different token types.

Y. Chen [76] analyses tokens as means of compensation, but that author limits the analysis to open-source developers participating in a project. However, there are no restrictions preventing the use of tokens for compensation for all employees. This would be useful for private companies that have no publicly-traded shares. If a company replicates shares with security tokens, those tokens may become de facto tradable securities available for sale $24 / 7$, with small increments. This solution would mitigate the principal-agent for private companies. On top of serving as securities for private companies, security tokens offer the same benefits as recording transactions with securities using blockchain, i.e., an opportunity to enable the real time tracking of ownership, which we discussed earlier.

Currently there are several pilot implementations of security tokens for corporate securities. The first platform that allowed clients to trade security tokens based on actual companies' shares was the Estonia-based platform DX.Exchange, backed by Nasdaq. The platform started by offering tokens linked to Nasdaq-traded stocks with an ambition to include stocks traded on other exchanges. The benefit highlighted by the platform is its $24 / 7$ availability for trading in securities, in contrast to the limited trading time offered by traditional exchanges [77].

The most recent one (at the time this article is written) is IX platform, backed by Singapore Exchange, which went live in July 2019. The platform (supported by an Ethereum startup, ConsenSys) "provides an IPO-like platform for private companies to raise capital and to increase liquidity in the primary capital market by using a public blockchain to validate transactions" [78]. On the platform, each token represents a company's security.

Even though security tokens offer the benefits discussed above, there are also risks. Multiple authors point out that the regulation is currently not always clear on the legal 
status of various types of tokens, which creates risks for the investors [20; 75].

N. Rückeshäuser [72] argues that while direct voting by the token owners empowers owners to have a direct influence on the firm's activity, not all the owners want to have such an influence and hence would just follow the managerial proposition. This could further increase the power of management, making the conflict even more radical than before.

We conclude this part of the article with a special type of conflict - investor activism. This may be caused by any of the reasons described above, but an overview of the literature shows that blockchain influences it in a special way.

\section{Shareholder activism}

The most extreme case of the principal-agent conflict, often creating a lot of media attention, is investor activism [79] and insider activism - activist campaigns initiated by insider owners such as founders [80]. Cases of activism occur more and more frequently, even though shareholders mostly try to hold private conversations with management before going to more extreme lengths [81; 82].

Investor activist campaigns usually include accumulation of a share in a target company that allows an activist to block certain managerial decisions and push his own. Activists often try to keep the information of their ownership private as long as possible in order to maximise the gain. If a company's stock is recorded on a blockchain instead of traditional ledgers [9] or if the company uses security tokens to enhance the liquidity of shares, this increases transparency of ownership due to the immediate nature of blockchain-based transactions. Traditionally it takes several days to process and record a change in ownership with a company's security. With blockchain-based recording, such changes become immediately visible. Hence, an activist would not be able to accumulate a significant share without a market reaction. However, there is an important nuance to this argument. To create maximum transparency, the blockchain application would need to be non-anonymous. If the blockchain application used would be analogous to Bitcoin, which allows a relative anonymity of transactions, this would simplify the accumulation of stock and hence increase the chance of an activist campaign against a company.

Another argument as to why blockchain should decrease the level of conflict and the likelihood of investor activism is the presence of abnormal returns generated by the hype wave associated with blockchain. D. Pollock [83] collects a series of examples of where shares experience extreme abnormal returns following the change of name of a company or a statement that the company is now focusing on blockchain. Prominent investment banks such as J.P. Morgan [84] suggest that firms would benefit from blockchain technology, creating additional confidence for the investors.

On the other hand, there are arguments as to why blockchain application may intensify the conflict. Blockchain and smart contracts are still at the early stage of development. There is still limited evidence that implementation creates immediate value, but there have been colourful failed attempts like the DAO investment fund discussed earlier.

Booms and bursts on cryptocurrencies markets, paired with lack of legal clarity $[15 ; 16 ; 85 ; 86]$ further contribute to uncertainty. This lack of certainty may scare shareholders and make them oppose managerial efforts to implement blockchain.

As with the dynamics underlying the shareholder-manager conflict, a systematic empirical analysis of the impact of blockchain implementation on the chances of shareholder activism against a company is currently lacking.

Overall, our literature overview shows that while most authors agree that blockchain has the potential to mitigate the principal-agent conflict, it can also create situations where the conflict may get stronger. For all three types of conflict surveyed, most of the works are conceptual. Quantitative proof of the influence of blockchain on the conflict, and hence on the quality of corporate governance for an organisation, is yet to be conducted.

\section{Actions necessary to maximise the value of blockchain implementation}

Blockchain is among the top digital technologies that top-management teams and boards of directors have to monitor closely [87].

Although our review shows a lack of quantitative proof of the positive influence of blockchain on corporate governance, one thing is certain: to embrace the potential benefits, firms need to choose the optimal way to implement blockchain and develop a set of competencies that enable them to benefit while mitigating the risks. While these topics are normally a subject of computer science or managerial literature, we still believe it is important to briefly address this in the final section of this article.

There are many features and nuances defining how blockchain implementation looks in a particular case. While many of those features are of a technical nature (approaches to consensus, structure of a block, etc.) [88], there is an important managerial decision to be made. That is, whether the company will implement a private, public, or a consortium blockchain. Blockchain is essentially a ledger that can only be updated once there is a consensus among the members. The type of blockchain essentially defines who are the members participating in the consensus process. In a public blockchain, all records are visible to the public and everyone can participate. In a private blockchain the creating organisation determines who can participate. The consortium blockchain is essentially a private blockchain, created by several organisations.

This choice will define the main characteristics of a blockchain, including the degree of information immutability, efficiency, and the degree of centralisation. For example, a private blockchain is the most centralised and efficient 
choice as it requires relatively few members to reach a consensus to update, but this makes it easier to tweak information in it [89].

R. Beck and C. Müller-Bloch [90] point out that for successful blockchain implementation, a firm needs to develop a skillset for radical innovation that includes skills for discovery, incubation and acceleration. However, the authors acknowledge that blockchain implementation as a technological project is unique as it requires cooperation not only within an organisation, but also with other organisations.

S. Wang et al. [24] offer a different perspective on the question of the governance of blockchain projects. The authors view popular cryptocurrencies as organisations rather than an asset class. Such organisations generate value by creating transparency in the process of economic exchange. The authors discuss optimal governance solutions in light of this and provide empirical evidence that investors value the cryptocurrencies' core value proposition, which is rooted in decentralisation. However, investors are suspicious of decentralised governance at higher levels in the organisation because they could slow down strategic decision-making. These and related works [e.g. 17; 91] do not analyse ordinary organisations and do not include an empirical analysis of whether investors respond positively to the movement toward the blockchain by traditional organisations.

Yet, there are many important questions from the corporate governance perspective that are currently not sufficiently covered in research literature. What are the technical capabilities that firms need to build to successfully implement a blockchain solution. For example, are they different from other IT projects? What is an optimal way to govern a blockchain? Should there be a special board of directors committee, or a special unit in the organisation or a blockchain subsidiary? What is an optimal way to staff a blockchain implementation project? Should an industry professional be hired as a board member or a member of top-management, or should a startup be bought with an established team? These questions leave ample room for further research on this topic, and demonstrate further how the field is still in a nascent stage.

\section{Conclusion}

In this article, we surveyed the recent studies on the implications of blockchain for corporate governance. This field is relatively new and the scholarly literature is only just emerging. We focused on three corporate governance aspects affected by the blockchain application: 1) the organisational environment, and the creation of the conflict; 2) common observable instances of conflict; and 3) actions necessary to maximise the value of blockchain implementation.

Most studies surveyed indicate that blockchain has the potential to mitigate the conflict. Corporate voting based on blockchain can involve more shareholders in the process of governance, thus improving the organisation- al dynamics causing the conflict. Using blockchain as a ledger to record transactions with a company's securities creates transparency in shares ownership, which should make conflicts concerning shareholder votes rarer. Using blockchain in a form of smart contracts offers innovative solutions related to the elections of the board of directors and compensation schemes. There are multiple practical implementations by serious industry participants which confirm potential blockchain benefits. However, as much as blockchain is a promising solution, it creates new challenges that companies will need to address.

The evidence that we found opens broad perspectives for further quantitative research. In particular, it poses at least six questions for corporate governance. 1) How does blockchain implementation affect monitoring activity by shareholders? 2) How does blockchain implementation affect the principal-agent relationship between managers and shareholders? 3) What is the impact of blockchain investment on the likelihood of a firm being the target of an activist campaign? 4) How does blockchain technology change the relationship between the firm and stakeholders, such as clients, suppliers, employees, etc.?

5) How does blockchain technology influence traditional corporate risks? 6) What are the proactive and reactive measures boards of directors need to implement in order to mitigate the technology-related risks of blockchain application? We intend to address these questions with empirical evidence in future research.

\section{References}

1. Jensen M., Meckling W. Theory of the firm: Managerial behavior, agency costs and ownership structure. Journal of Financial Economics. 1976;3(4):305-360. DOI: 10.1016/0304-405X(76)90026-X

2. Berle A., Means G. The modern corporation and private property. New York: The Macmillan Co.; 1932. $428 \mathrm{p}$.

3. Aghion P., Van Reenen J., Zingales L. Innovation and institutional ownership. American Economic Review. 2013;103(1):277-304. DOI: 10.1257/aer.103.1.277

4. Ertimur Y., Ferri F., Stubben S.R. Board of directors' responsiveness to shareholders: Evidence from shareholder proposals. Journal of Corporate Finance. 2010;16(1):53-72. DOI: 10.1016/j. jcorpfin.2009.07.005

5. Brav A, Jiang W, Partnoy F, Thomas R. Hedge fund activism, corporate governance, and firm performance. The Journal of Finance. 2008;63(4):1729-1775. DOI: 10.1111/j.15406261.2008.01373.x

6. Klein A., Zur E. Entrepreneurial shareholder activism: Hedge funds and other private investors. The Journal of Finance. 2009;64(1):187-229. DOI: 10.2139/ssrn.913362 
7. Jensen M.C., Smith C.W. Stockholder, manager, and creditor interests: Applications of agency theory. SSRN Electronic Journal. 1985. DOI: 10.2139/ ssrn. 173461

8. Hill C.W., Jones T.M. Stakeholder-agency theory. Journal of Management Studies. 1992;29(2):131-154.

9. Yermack D. Corporate governance and blockchains. Review of Finance. 2017;21(1):7-31. DOI: 10.1093/ rof/rfw074

10. Cong L., He Z. Blockchain disruption and smart contracts. The Review of Financial Studies. 2019;32(5):1754-1797. DOI: 10.1093/rfs/hhz007

11. Blockchain: The next big thing. Or is it? The Economist. 2015. URL: http://www.economist.com/ news/special-report/21650295-orit-next-big-thing

12. Swan M. Blockchain: Blueprint for a new economy. Sebastopol, CA: O’Reilly Media, Inc.; 2015. 152 p.

13. Tang H, Shi Y, Dong P. Public blockchain evaluation using entropy and TOPSIS. Expert Systems with Applications. 2019;117:204-210. DOI: 10.1016/j. eswa.2018.09.048

14. Li X., Jiang P., Chen T., Luo X., Wen Q. A survey on the security of blockchain systems. Future Generation Computer Systems. 2017. DOI: 10.1016/j. future.2017.08.020

15. Böhme R., Christin N., Edelman B., Moore T. Bitcoin: Economics, technology, and governance. Journal of Economic Perspectives. 2015;29(2):213-238. DOI: 10.1257/jep.29.2.213

16. Cagli E.C. Explosive behavior in the prices of Bitcoin and altcoins. Finance Research Letters. 2019;29:398403. DOI: 10.1016/j.frl.2018.09.007

17. Hsieh Y.Y., Vergne J.P., Anderson P., Lakhani K., Reitzig M. Bitcoin and the rise of decentralized autonomous organizations. Journal of Organization Design. 2018;7(14). DOI: 10.1186/s41469-018-0038-1

18. Holub M., Johnson J. Mapping bitcoin's influence on academic research. SSRN Electronic Journal. 2017. DOI: $10.2139 /$ ssrn.3094492

19. Hawlitschek F., Notheisen B., Teubner T. The limits of trust-free systems: A literature review on blockchain technology and trust in the sharing economy. Electronic Commerce Research and Applications. 2018;29:50-63. DOI: 10.1016/j.elerap.2018.03.005

20. Magnier V., Barban P. The potential impact of blockchains on corporate governance: A survey on shareholders' rights in the digital era. InterEULawEast: Journal for the International and European Law, Economics and Market Integrations. 2018;5(2):189-226. DOI: 10.22598/iele.2018.5.2.7

21. Macrinici D., Cartofeanu C., Gao S. Smart contract applications within blockchain technology:
A systematic mapping study. Telematics and Informatics. 2018;35(8):2337-2354. DOI: 10.1016/j. tele.2018.10.004

22. Lee L. New kids on the blockchain: How bitcoin's technology could reinvent the stock market. Hastings Business Law Journal. 2016;12(2):81-132.

23. Szabo N. Formalizing and securing relationships on public networks. First Monday. 1997;2(9). URL: https://ojphi.org/ojs/index.php/fm/article/ view/548/469

24. Hsieh Y.-Y., Vergne J.-P., Wang S., The internal and external governance of blockchain-based organizations: Evidence from cryptocurrencies. In: Campbell-Verduyn M., ed. Bitcoin and beyond: Blockchains and global governance. London: Routledge; 2017:48-68. (RIPE Series in Global Political Economy).

25. Buterin V. DAOs, DACs, DAs and more: An incomplete terminology guide. Ethereum Blog. 2014. URL: https://blog.ethereum.org/2014/05/06/daosdacs-das-and-more-an-incomplete-terminologyguide/

26. Malinova K., Park A. Market design with blockchain technology. SSRN Electronic Journal. 2017. DOI: $10.2139 /$ ssrn.2785626

27. Caytas J. Developing blockchain real-time clearing and settlement in the EU, U.S., and globally. Columbia Journal of European Law: Preliminary Reference. 2016. URL: http://cjel.law.columbia.edu/ preliminary-reference/2016/developing-blockchainreal-time-clearing-and-settlement-in-the-eu-u-sand-globally- $2 /$ ?cn-reloaded $=1$

28. Min H. Blockchain technology for enhancing supply chain resilience. Business Horizons. 2019;62(1):35-45. DOI: 10.1016/j.bushor.2018.08.012

29. Ølnes S., Ubacht J., Janssen M. Blockchain in government: Benefits and implications of distributed ledger technology for information sharing. Government Information Quarterly. 2017;34(3):355364. DOI: 10.1016/j.giq.2017.09.007

30. Andoni M., Robu V., Flynn D., Abram S., Geach D., Jenkins D., McCallum P., Peacock A. Blockchain technology in the energy sector: A systematic review of challenges and opportunities. Renewable and Sustainable Energy Reviews. 2019;100:143-174. DOI: 10.1016/j.rser.2018.10.014

31. DuPont Q. Experiments in algorithmic governance: A history and ethnography of "The DAO", a failed decentralized autonomous organization. In: Campbell-Verduyn M., ed. Bitcoin and beyond: Blockchains and global governance. London: Routledge; 2017:157-177. (RIPE Series in Global Political Economy). 
32. Kristof A. Autonomous finance. In: Chuen D.L.K., Deng R., eds. Handbook of blockchain, digital finance, and inclusion. Vol. 2: ChinaTech, mobile security, and distributed ledger. London, San Diego, CA: Academic Press; 2017:471-479.

33. Jensen M. The modern industrial revolution, exit, and the failure of internal control systems. The Journal of Finance. 1993;48(3):831-880

34. Shleifer A., Vishny R.W. A survey of corporate governance. The Journal of Finance. 1997;52(2):737783.

35. Coles J.L., Daniel N.D., Naveen L. Co-opted boards. The Review of Financial Studies. 2014;27(6):17511796. DOI: $10.1093 / \mathrm{rfs} / \mathrm{hhu} 011$

36. Roe M.J. A political theory of American corporate finance. Columbia Law Review. 1991;91(1):10-67. DOI: $10.2307 / 1122856$

37. Shleifer A, Vishny R.W. Large shareholders and corporate control. Journal of Political Economy. 1986;94(3, Pt. 1):461-488. DOI: 10.1086/261385

38. Fich E.M., Harford J., Tran A.L. Motivated monitors: The importance of institutional investors portfolio weights. Journal of Financial Economics. 2015;118(1):21-48. DOI: 10.1016/j. jifineco.2015.06.014

39. Iliev P., Lowry M. Are mutual funds active voters? The Review of Financial Studies. 2015;28(2):446-485. DOI: $10.1093 /$ rfs/hhu062

40. Malenko N., Shen Y. The role of proxy advisory firms: Evidence from a regression-discontinuity design. The Review of Financial Studies. 2016;29(12):3394-3427. DOI: $10.1093 / \mathrm{rfs} / \mathrm{hhw} 070$

41. Van der Elst C. Revisiting shareholder activism at AGMs: Voting determinants of large and small shareholders. European Corporate Governance Institute (ECGI) Finance Working Paper. 2011;(311). URL: https://ecgi.global/sites/default/files/working_ papers/documents/SSRN-id1886865.pdf

42. Cvijanović D., Groen-Xu M., Zachariadis K.E. Freeriders and underdogs: Participation in corporate voting. 2017. URL: https://editorialexpress. com/cgi-bin/conference/download.cgi?db_ name=AFA2018\&paper_id $=1030$

43. Kahan M., Rock E. The hanging chads of corporate voting. The Georgetown Law Journal. 2008;96(4):1227-1281. URL: https://scholarship.law. upenn.edu/cgi/viewcontent.cgi? article $=1163 \&$ context =faculty_scholarship

44. Aldrich J.H. Rational choice and turnout. American Journal of Political Science. 1993;37(1):246-278. DOI: $10.2307 / 2111531$
45. Van der Elst C., Lafarre A. Bringing the AGM to the $21^{\text {st }}$ century: Blockchain and smart contracting tech for shareholder involvement. European Corporate Governance Institute (ECGI) Law Working Paper. 2017;(358). URL: https://ecgi.global/sites/default/ files/working_papers/documents/3582017.pdf

46. Wright A., De Filippi P. Decentralized blockchain technology and the rise of lex cryptographia. SSRN Electronic Journal. 2015. DOI: 10.2139/ssrn.2580664

47. Lafarre A., Van der Elst C. Blockchain technology for corporate governance and shareholder activism. European Corporate Governance Institute (ECGI) Law Working Paper. 2018;(390). DOI: 10.2139/ ssrn.3135209

48. Kaal W.A. Blockchain solutions for agency problems in corporate governance. In: Balachandran K.R., ed. Economic information to facilitate decision making. 2019. URL: https://papers.ssrn.com/sol3/papers. cfm?abstract_id=3373393

49. Piazza F.S. Bitcoin and the blockchain as possible corporate governance tools: Strengths and weaknesses. Penn State Journal of Law \& International Affairs. 2017;5(2):262-301. URL: https://elibrary.law.psu.edu/cgi/viewcontent. cgi? article $=1163 \&$ context $=$ jlia

50. De Falco S.E., Cucari N., Canuti E., Modena S. Corporate governance and blockchain: Some preliminary results by a survey. In: Proc. Int. conf. "Corporate governance: Search for the advanced practices" (Rome, Feb. 28, 2019). 2019:102-115. URL: https://virtusinterpress.org/IMG/pdf/cpr19p3.pdf

51. McCorry P., Shahandashti S.F., Hao F. A smart contract for boardroom voting with maximum voter privacy. In: Proc. $21^{\text {st }}$ Int. conf. on Financial Cryptography and Data Security. Cham: SpringerVerlag; 2017:357-375. URL: https://eprint.iacr. org/2017/110.pdf

52. Tarasov P., Tewari H. The future of e-voting. IADIS International Journal on Computer Science \& Information Systems. 2017;12(2):148-165. URL: http://www.iadisportal.org/ijcsis/papers/2017210210. pdf

53. Mainelli M., Milne A.K.L. The impact and potential of blockchain on the securities transaction lifecycle. SWIFT Institute Working Paper. 2016;(2015007). URL: https://swiftinstitute.org/wp-content/ uploads/2016/05/The-Impact-and-Potential-ofBlockchain-on-the-Securities-Transaction-Lifecycle_ Mainelli-and-Milne-FINAL-1.pdf

54. ICJ and Broadridge execute the first blockchainbased interoperable proxy voting process in Japan. Broadridge. 2019. URL: https://www.broadridge.com/ intl/press-release/2019/icj-and-broadridge-executethe-proxy-voting-process (accessed on 26.09.2019). 
55. SWIFT launches DLT e-voting PoC. SWIFT. 2019. URL: https://www.swift.com/news-events/pressreleases/swift-launches-dlt-e-voting-poc

56. Gillan S.L., Starks L.T. Corporate governance proposals and shareholder activism: The role of institutional investors. Journal of Financial Economics. 2000;57(2):275-305. DOI: 10.1016/S0304405X(00)00058-1

57. Buchanan B., Netter J.M., Yang T. Are shareholder proposals an important corporate governance device? Evidence from US and UK shareholder proposals. SSRN Electronic Journal. 2015. DOI: 10.2139/ ssrn. 1572016

58. Babenko I, Choi G, Sen R. Management (of) proposals. URL: https://pdfs.semanticscholar.org/2a4d/a4b67d616 370d09762eb2e66069043f2bd4c.pdf

59. Grove H., Patelli L., Victoravich L.M., Xu P. Corporate governance and performance in the wake of the financial crisis: Evidence from US commercial banks. Corporate Governance: An International Review. 2011;19(5):418-436. DOI: 10.1111/j.14678683.2011.00882.x

60. Ciampi F. Corporate governance characteristics and default prediction modeling for small enterprises. An empirical analysis of Italian firms. Journal of Business Research. 2015;68(5):1012-1025. DOI: 10.1016/j. jbusres.2014.10.003

61. Beck T., Behr P., Guettler A. Gender and banking: Are women better loan officers? Review of Finance. 2013;17(4):1279-1321. DOI: 10.1093/rof/rfs028

62. Mehran H. Executive compensation structure, ownership, and firm performance. Journal of Financial Economics. 1995;38(2):163-184. DOI: 10.1016/0304-405X(94)00809-F

63. Peters G.W., Panayi E. Understanding modern banking ledgers through blockchain technologies: Future of transaction processing and smart contracts on the internet of money. In: Tasca P., Aste T., Pelizzon L., Perony N., eds. Banking beyond banks and money: A guide to banking services in the twenty-first century. Cham: Springer-Verlag; 2016:239-278.

64. Warther V.A. Board effectiveness and board dissent: A model of the board's relationship to management and shareholders. Journal of Corporate Finance. 1998;4(1):53-70. DOI: 10.1016/S09291199(97)00009-6

65. Herman E.S. Corporate control, corporate power: A twentieth century fund study. London, New York: Cambridge University Press; 1981. 452 p.

66. Whisler T.L. Rules of the game: Inside the corporate boardroom. Homewood, IL: Dow Jones-Irwin; 1984. $95 \mathrm{p}$.
67. Mace M.L. Directors, myth and reality. Boston, MA: Harvard Business School Press; 1986. 208 p.

68. Rosenstein S., Wyatt J.G. Outside directors, board independence, and shareholder wealth. Journal of Financial Economics. 1990;26(2):175-191. DOI: 10.1016/0304-405X(90)90002-H

69. Chedrawi C., Howayeck P. Audit in the blockchain era within a principal-agent approach. In: Information and communication technologies in organizations and society (ICTO 2018): "Information and communications technologies for an inclusive world" (Paris, March 22-23, 2018). 2018. URL: https://www.researchgate.net/ publication/323987299_Audit_in_the_Blockchain_ era_within_a_principal-agent_approach

70. Xie B., Davidson W.N. III, DaDalt P.J. Earnings management and corporate governance: The role of the board and the audit committee. Journal of Corporate Finance. 2003;9(3):295-316. DOI: 10.1016/ S0929-1199(02)00006-8

71. Byström H. Blockchains, real-time accounting, and the future of credit risk modeling. Department of Economics, Lund University. Working Paper. 2016;(4). URL: https://project.nek.lu.se/publications/ workpap/papers/wp16_4.pdf

72. Rückeshäuser N. Do we really want blockchain-based accounting? Decentralized consensus as enabler of management override of internal controls. 2017. URL: https://wi2017.ch/images/wi2017-0112.pdf

73. The Attacker. An open letter. Pastebin.com. 2016. URL: https://pastebin.com/CcGUBgDG

74. Enayati H., Hallock K.F., Barrington L. TSR, executive compensation, and firm performance. 2015. URL: https://www.ilr.cornell.edu/sites/default/files/ ICS_TSR_Brief_Oct_15.pdf

75. Oliveira L., Zavolokina L., Bauer I., Schwabe G. To token or not to token: Tools for understanding blockchain tokens. 2018. URL: https://www.zora. uzh.ch/id/eprint/157908/1/To\%20Token\%20 or\%20not\%20to\%20Token_\%20Tools\%20for\%20 Understanding\%20Blockchain\%20Toke.pdf

76. Chen Y. Blockchain tokens and the potential democratization of entrepreneurship and innovation. Business Horizons. 2018;61(4):567-575. DOI: 10.1016/j.bushor.2018.03.006

77. Huillet M. Nasdaq-powered EU digital exchange DX launches security token trading. Cointelegraph.com. 2019. URL: https://cointelegraph.com/news/nasdaqpowered-eu-digital-exchange-dx-launches-securitytoken-trading (accessed on 26.09.2019).

78. Zhao W. Singapore's stock exchange backs new Ethereum security token platform. Coindesk. 2019. URL: https://www.coindesk.com/singapores-stock- 
exchange-backs-new-ethereum-security-tokenplatform (accessed on 26.09.2019).

79. Clifford C.P. Value creation or destruction? Hedge funds as shareholder activists. Journal of Corporate Finance. 2008;14(4):323-336. DOI: 10.1016/j. jcorpfin.2008.04.007

80. Cohn J.B., Towner M., Virani A. Quasi-insider shareholder activism: Corporate governance at the periphery of control. 2017. URL: http://www. mitchtowner.com/quasi-insider_2017dec14.pdf

81. McCahery J., Sautner Z., Starks L. Behind the scenes: The corporate governance preferences of institutional investors. The Journal of Finance. 2016;71(6):29052932. DOI: $10.1111 /$ jofi.12393

82. Levit D. Soft shareholder activism. The Review of Financial Studies. 2019;32(7):2775-2808. DOI: 10.1093/rfs/hhy119

83. Pollock D. Wonders of naming the company 'Blockchain' or 'Bitcoin'. Cointelegraph.com. 2018. URL: https://cointelegraph.com/news/wonders-ofnaming-the-company-blockchain-or-bitcoin

84. Rooney K. J.P. Morgan sees three potential long-term stock winners from blockchain. 2018. URL: https:// www.cnbc.com/2018/11/08/jp-morgans-threepotential-winners-in-blockchain.html

85. Kajtazi A., Moro A. The role of bitcoin in well diversified portfolios: A comparative global study. International Review of Financial Analysis. 2019;61:143-157. DOI: 10.1016/j.irfa.2018.10.003
86. Fry J. Booms, busts and heavy-tails: The story of Bitcoin and cryptocurrency markets? Economics Letters. 2018;171:225-229. DOI: 10.1016/j. econlet.2018.08.008

87. Grove H., Clouse M., Schaffner L.G. Digitalization impacts on corporate governance. Journal of Governance \& Regulation. 2018;7(4):51-63. DOI: 10.22495/jgr_v7_i4_p6

88. Xu X., Weber I., Staples M., Zhu L., Bosch J., Bass L., Pautasso C., Rimba P. A taxonomy of blockchainbased systems for architecture design. In: 2017 IEEE Int. conf. on software architecture (ICSA) (Gothenburg, Apr. 3-7, 2017). New York: IEEE; 2017:243-252. DOI: 10.1109/ICSA.2017.33

89. Zheng Z., Xie S., Dai H.N., Chen X., Wang H. Blockchain challenges and opportunities: A survey. International Journal of Web and Grid Services. 2018;14(4):352-375. DOI: 10.1504/ IJWGS.2018.095647

90. Beck R., Müller-Bloch C. Blockchain as radical innovation: A framework for engaging with distributed ledgers as incumbent organization. In: Proc. 50 ${ }^{\text {th }}$ Hawaii int. conf. on system sciences. 2017. DOI: $10.24251 /$ hicss.2017.653

91. De Filippi P., Loveluck B. The invisible politics of bitcoin: Governance crisis of a decentralized infrastructure. Internet Policy Review. 2016;5(3). DOI: 10.14763/2016.3.427 